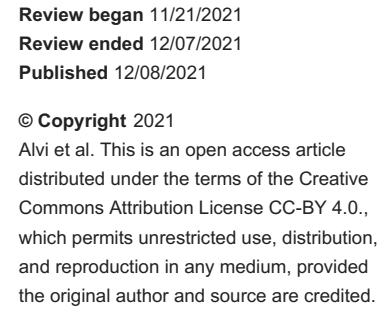

\section{Primary Amenorrhea With Hypothyroidism: Finding the Cause}

\author{
Asim Munir Alvi ${ }^{1}$, Ahmed Imran Siddiqi ${ }^{2}$, Umal Azmat ${ }^{2}$, Waqas Shafiq ${ }^{2}$, Sardar A. Khan ${ }^{3}$ \\ 1. Endocrinology, Diabetes and Metabolism, Shaukat Khanum Memorial Cancer Hospital and Research Centre, Lahore, \\ PAK 2. Endocrinology and Diabetes, Shaukat Khanum Memorial Cancer Hospital and Research Centre, Lahore, PAK 3. \\ Endocrinology, Shaukat Khanum Memorial Cancer Hospital and Research Centre, Lahore, PAK
}

Corresponding author: Asim Munir Alvi, asimalvi970@yahoo.com

\begin{abstract}
Primary amenorrhea is a serious medical condition. A thorough clinical assessment is necessary for a timely and correct diagnosis and management of this ailment to prevent long-term health and social problems. Turner's syndrome is considered one of the important causes of primary amenorrhea, with an incidence of one in 2,500 to one in 3,000 live-born girls. In this report, we present an interesting case involving multinodular goiter, hypothyroidism, and primary amenorrhea.
\end{abstract}

A 24-year-old woman with a history of multinodular goiter and hypothyroidism attended an endocrine clinic with fine-needle aspiration cytology (FNAC) report of her bilateral thyroid nodules, which showed Bethesda category IV. She had a history of learning difficulties. During detailed history-taking, the patient also complained of primary amenorrhea. Clinical examination showed a lack of secondary sexual characters. Biochemical, imaging, and cytogenetic investigations were suggestive of absent ovaries and fallopian tubes, streaked uterus, hypergonadotropic hypogonadism, and X0 karyotyping.

The learning objectives of this case report are as follows: firstly, in countries with a lack of awareness and limited health resources, patients may present with one of the manifestations of Turner's syndrome. Clinicians from all specialties should be aware of the clinical features of this relatively rare entity and should try to make the most of incidental clinical findings. Secondly, clinicians should be more vigilant and thorough in their clinical assessment of patients with learning difficulties to minimize the chances of missing a clinical diagnosis.

Categories: Endocrinology/Diabetes/Metabolism, Internal Medicine

Keywords: turner syndrome, hypergonadotropic hypogonadism, hypothyroidism, multinodular goiter, primary amenorrhea

\section{Introduction}

Amenorrhea is a serious clinical problem both for patients and clinicians and is defined as the absence of menstruation in females of reproductive age [1]. Primary amenorrhea is characterized by the absence of menarche (start of menstruation) in females of 15 years or older having secondary sexual characters and normal growth or the absence of menarche in females of 13 years or older without signs of pubertal development [2]. Secondary amenorrhea is defined as the loss of regular menses for three months or loss of irregular menses for six months after menarche [3].

According to the World Health Organization (WHO), amenorrhea is the sixth most common cause of infertility, and around 2-5\% of adolescent girls are affected by primary amenorrhea. Its incidence has been on the rise due to an increase in general awareness, improving health facilities, and decreasing trend of child marriages [1]. Primary amenorrhea can occur due to pituitary disorders resulting in hypogonadotropic hypogonadism, disorders of gonads leading to hypergonadotropic hypogonadism, other endocrine glands diseases, or uterovaginal anomalies. Clinical investigations of primary amenorrhea are warranted when there is no menstruation for three years after thelarche (start of breast development) or after five years of thelarche if it has happened before the age of 10 years [2]. We discuss an interesting case of a patient who presented with multinodular goiter, hypothyroidism, and primary amenorrhea.

\section{Case Presentation}

A 24-year-old woman, diagnosed with multinodular goiter and hypothyroidism, presented to the endocrine clinic. She was already on thyroxin replacement. She was also clinically and biochemically euthyroid. Her fine needle aspiration cytology (FNAC) report of bilateral thyroid nodules showed Bethesda category IV. Primary amenorrhea was an incidental finding in her case. There was no evidence of stress, anxiety, depression, or weight changes. She had no history of strenuous exercise or abnormal eating behavior. She denied any history of cyclical abdominal pain, head trauma, headache, visual problems, and galactorrhea. There was no history of radiation to the brain and chemotherapy. She had been born of consanguineous 


\section{Cureus}

marriage. All her nine sisters had achieved menarche between the ages of 12 and 13 years. Her mother also had normal menstrual history. The patient had learning difficulties and had not attended school due to this.

On examination, she had short stature with a webbed neck. She had minimal axillary hair, pubic hair (Tanner stage 1), no breast development (Tanner stage 1), a high arch palate, and squint. The external genital examination was unremarkable. Her BMI was $20 \mathrm{~kg} / \mathrm{m}^{2}$. Table 1 illustrates her hormonal profile, as well as imaging and karyotyping results.

\begin{tabular}{|c|c|c|}
\hline Test name & Value & $\begin{array}{l}\text { Reference } \\
\text { range }\end{array}$ \\
\hline Luteinizing hormone (LH) & $17.6 \mathrm{mlU} / \mathrm{mL}$ & $1.1-14.7$ \\
\hline Follicle-stimulating hormone (FSH) & 130 mIU/mL & $2.8-11.3$ \\
\hline Estradiol & $28.67 \mathrm{pg} / \mathrm{mL}$ & $19.5-214$ \\
\hline $\begin{array}{l}\text { Dehydroepiandrosterone sulfate } \\
\text { (DHEA-SO4) }\end{array}$ & $68.9 \mathrm{ug} / \mathrm{dL}$ & $35-430$ \\
\hline Prolactin & 11.4 ng/mL & $1.90-25$ \\
\hline Testosterone & 14.28 ng/dL & $12-59.4$ \\
\hline Cortisol & 17.52 mcg/dL & $5.27-22.45$ \\
\hline Thyroid-stimulating hormone (TSH) & 5.35 ulU/mL & $0.35-5.5$ \\
\hline Free T4 & $1.01 \mathrm{ng} / \mathrm{dL}$ & $0.89-1.76$ \\
\hline Ultrasound pelvis & Absent cervix, uterus, and bilateral ovaries & \\
\hline $\begin{array}{l}\text { Magnetic resonance imaging (MRI) } \\
\text { pelvis }\end{array}$ & $\begin{array}{l}\text { Extremely rudimentary uterus with streak-like configuration. No ovarian tissue } \\
\text { was identified }\end{array}$ & \\
\hline Echocardiography & Unremarkable study & \\
\hline Ultrasound thyroid & Multinodular goiter & \\
\hline Karyotyping & X0 & \\
\hline
\end{tabular}

TABLE 1: Hormonal profile, imaging, and karyotyping

Biochemical investigations confirmed hypergonadotropic hypogonadism, and imaging investigations (Figures 1,2) confirmed absent ovaries, fallopian tubes, and streaked uterus. 


\section{Cureus}

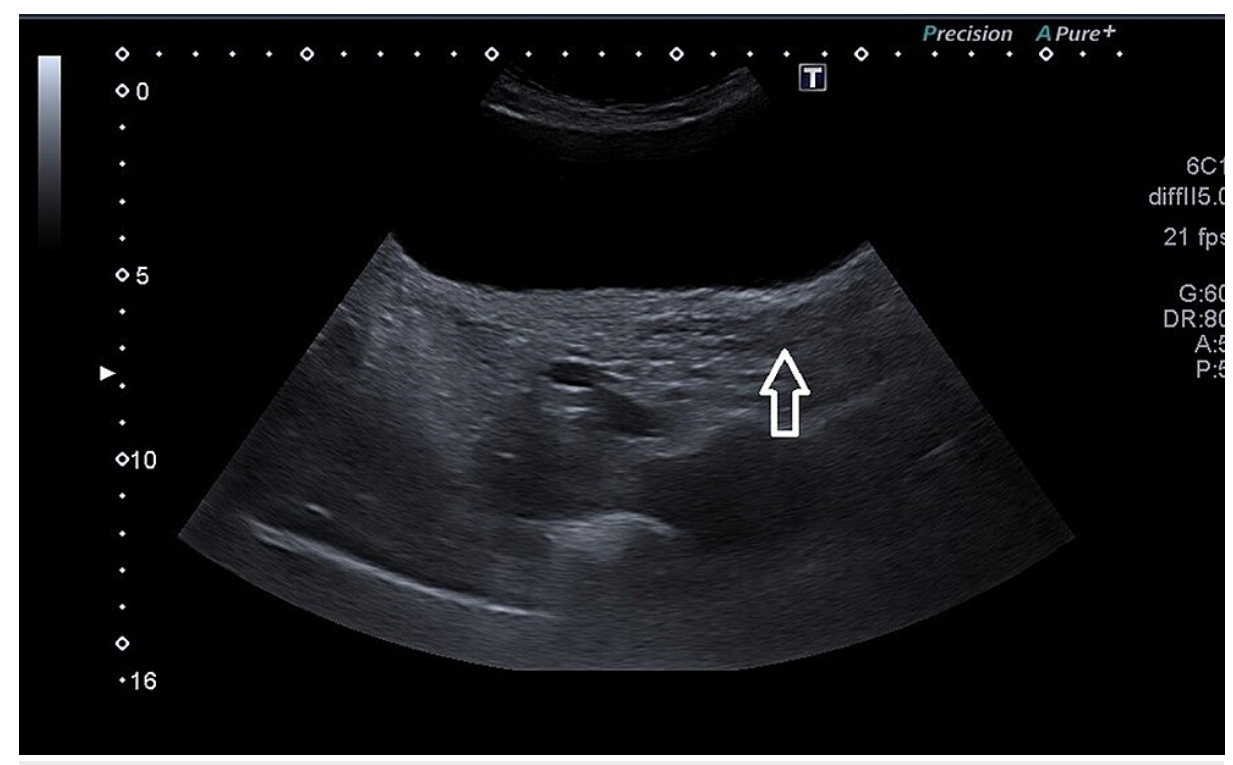

FIGURE 1: Ultrasound pelvis (arrow showing rudimentary uterus)

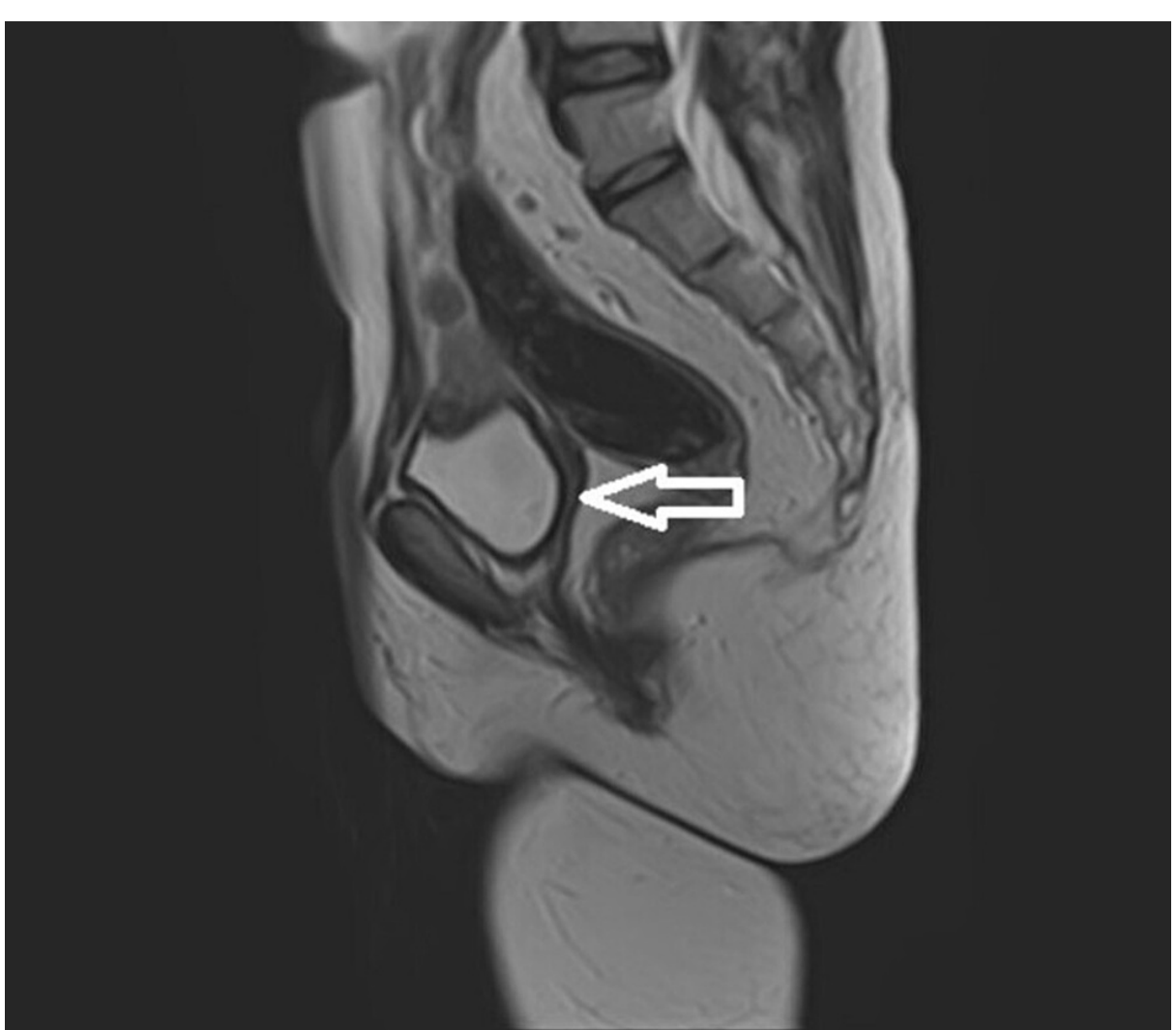

FIGURE 2: MRI abdomen and pelvis (arrow showing rudimentary uterus)

MRI: magnetic resonance imaging

X0 karyotyping result confirmed our clinical suspicion of Turner’s syndrome (Figure 3). 


\section{Cureus}

Specimen: Peripheral blood

Test performed : Chromosome Analysis, for Congenital Disorders, Blood

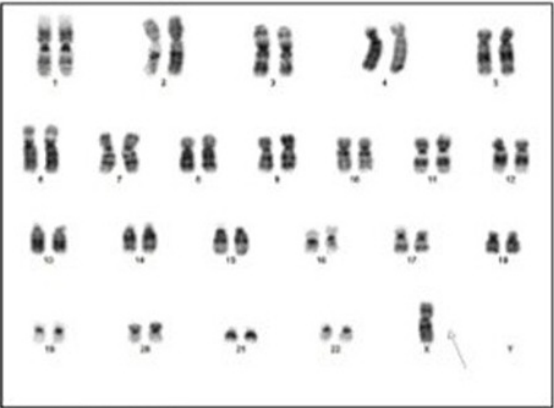

Karyotype: $45, \mathrm{X}$

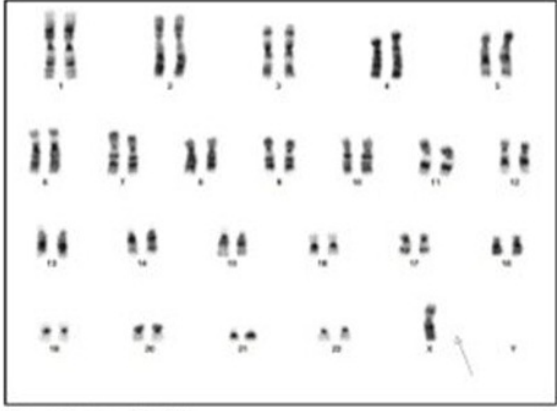

Karyotype: $45, X$

Specimen Volume: $4.0 \mathrm{~mL}$ in Lithium Heparin Cells Counted: 20

Cells Captured/Analyzed: 20/20
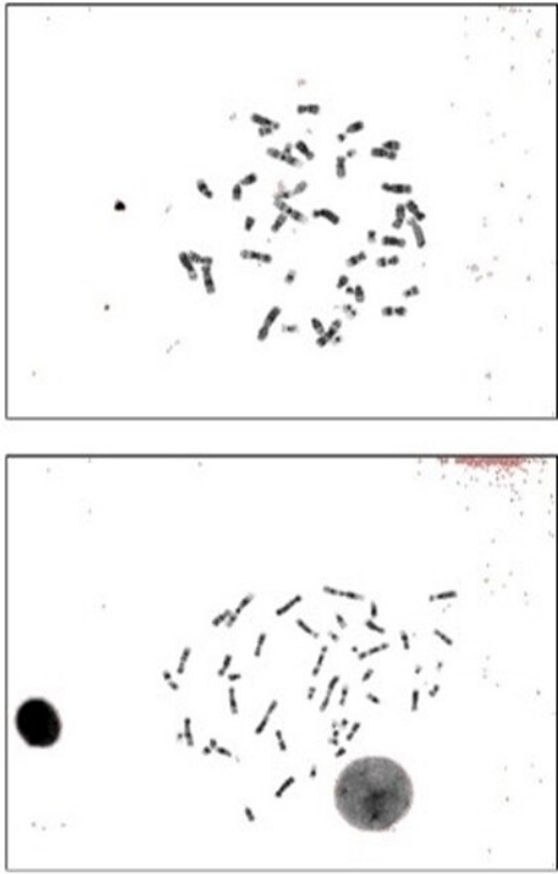

Date/Time Set-up: 23-08-2021 15:00 Cells Karyotyped: 07

Result:

GTG Banding 45,X[20]; Abnormal Female Karyotype

\section{FIGURE 3: Karyotyping (showing XO karyotype)}

The patient is currently receiving psychological support and counseling regarding her diagnosis and subsequent emotional issues with the support of her family. She was prescribed hormone replacement therapy with ethinylestradiol/levonorgestrel. We offered total thyroidectomy for her multinodular goiter in light of her bilateral Bethesda category IV nodules and she consented. Histopathology of thyroid tissue has shown adenomatous colloid goiter, and she is presently doing well under regular follow-up in the endocrinology department.

\section{Discussion}

There are many causes of primary amenorrhea, including hypogonadotropic hypogonadism, hypergonadotropic hypogonadism, and normogonadotropic hypogonadism (Table 2) [2-4]. 


\section{Cureus}

\section{Hypogonadotropic hypogonadism}

Constitutional delay/self-limited delayed puberty

Congenital hypogonadotropic hypogonadism (Kallmann syndrome)

Functional hypothalamic problems (anorexia nervosa, chronic diseases like celiac disease, IBD, strenuous exercise, stress, psychiatric issues)

Syndromic congenital hypogonadotropic hypogonadism (CHARGE syndrome, CAH, SOD, PWS, LMBBS)

Pituitary hormone deficiencies due to its destruction (benign adenomas and other tumors; cysts, infiltrative disorders, previous surgery, head trauma, pituitary apoplexy, vascular lesions, empty sella syndrome, radiation therapy)

Thyroid problems (hypothyroidism or hyperthyroidism)

\section{Hypergonadotropic hypogonadism}

Premature ovarian insufficiency/failure (Turner's syndrome, gonadal dysgenesis, autoimmune oophoritis, polyglandular autoimmune syndrome, radiation therapy, surgery, chemotherapy, infections)
Normogonadotropic hypogonadism

Pituitary

(hyperprolactinemia)

Adrenals (non-classic $\mathrm{CAH}$, androgensecreting tumors, Addison's disease)

Ovaries (PCOS androgen- or estrogen-secreting tumors)

Uterus (Müllerian structures agenesis cervical agenesis, AIS, pregnancy)

Vagina (atresia, transverse septum, distal atresia)

Imperforation of hymen

Medications (anesthetics, anticonvulsants, antipsychotics, opiates, anti-emetics, SSRIs, OCPs, alcohol abuse, heroin, cocaine, steroids, androgens use)

\section{TABLE 2: Causes of primary amenorrhea}

$\mathrm{CAH}$ : congenital adrenal hyperplasia; IBD: inflammatory bowel disease; PCOS: polycystic ovarian syndrome; SOD: septo-optic dysplasia; PWS: PraderWilli syndrome; LMMBS: Laurence-Moon-Bardet-Biedl syndrome; AIS: androgen insensitivity syndrome; OCPs: oral contraceptive pills; SSRIs: selective serotonin reuptake inhibitors

A systematic clinical approach is key to a proper assessment of patients presenting with primary amenorrhea, including thorough clinical history, complete physical examination, and examination of external and internal genitalia. Lab work should include thyroid-stimulating hormone (TSH), folliclestimulating hormone (FSH), luteinizing hormone (LH), estradiol, testosterone, beta-human chorionic gonadotropin (B-HCG), serum prolactin levels, and karyotyping (if clinically indicated. Perform karyotype in all patients of hypergonadotropic hypogonadism and with androgenic features) [2]. The hormonal profile of our patient showed hypergonadotropic hypogonadism, and this prompted us to perform karyotyping.

After complete history-taking, physical examination, and initial investigations of our patient, two main differentials were made: Turner's syndrome and Müllerian agenesis with ovarian failure as the cause of primary amenorrhea. In the ultrasonography pelvis report of our patient, ovaries and uterus were absent; Müllerian agenesis with ovarian failure was one of our differentials as there was a case reported in the literature that showed Müllerian agenesis with ovarian failure [5].

Patients with only Müllerian agenesis without ovarian failure (or gonadal dysgenesis) have normal secondary sexual characters with normal LH, FSH, and estradiol levels because gonads have different embryonic origins [5-6]. If secondary sexual characters are absent, together with the absence of internal sexual structure, then the diagnosis will be Müllerian agenesis [Mayer-Rokitansky-Küster-Hauser (MRKH) syndrome with gonadal dysgenesis] [5].

Turner's syndrome can present with primary amenorrhea and lack of secondary sexual characters if ovarian failure develops before the onset of puberty [7]. The lack of secondary sexual features in our patient was due to the absence of estrogen (ovarian failure) before the onset of puberty. About half of Turner's syndrome patients have only one $\mathrm{X}$ chromosome (45 X0) and 5-10\% have a doubling of the long arm of one $\mathrm{X}$ 


\section{Cureus}

(46,X,i(Xq)). Most of the other patients have mosaicism for 45, X, with one or more additional cell lineages [7]. Karyotyping result of our patient showed an X0 karyotype, which confirmed the diagnosis of Turner's syndrome. The diagnosis of Turner's syndrome should be considered in any teenage girl with primary or secondary amenorrhea, especially when she is short-statured. Clinically, Turner's syndrome can involve any system of the body (general, cardiovascular, endocrine, renal, gastrointestinal, musculoskeletal, dermatological, eye, and otorhinolaryngological) and can present with manifestations related to any system of the body (Table 3) [7].

\begin{tabular}{|c|c|}
\hline Systems/problems & Features that can be present in Turner's syndrome \\
\hline General & Short stature, mostly normal intelligence, female phenotype \\
\hline Cardiovascular & $\begin{array}{l}17-45 \% \text { have congenital heart diseases; aortic coarctation and bicuspid aortic valve are most common; others } \\
\text { include left-sided cardiac defects, hypertension, mitral valve prolapsed, and conduction defects }\end{array}$ \\
\hline Endocrine & Hypothyroidism; gonadal dysgenesis is a cardinal feature of Turner's syndrome; infertility, diabetes mellitus \\
\hline Eye, ENT problems & Strabismus, ptosis, cataract, nystagmus, color blindness, recurrent otitis media, sensorineural hearing loss \\
\hline $\begin{array}{l}\text { Gastrointestinal } \\
\text { problems }\end{array}$ & GERD, IBD, celiac disease, gall bladder disease \\
\hline Renal problems & Structural renal problems (horseshoe-shaped kidney, duplication of collecting system) \\
\hline $\begin{array}{l}\text { Musculoskeletal } \\
\text { problems }\end{array}$ & $\begin{array}{l}\text { Dislocation of patellar bone and pain in the knee joint; deformity of the ulnar head causes the increase-carrying } \\
\text { angle of the arm and may result in a decreased range of motion, Madelung's deformity, and congenital dislocation of } \\
\text { the hip, high arched palate, spinal deformities, and osteoporosis }\end{array}$ \\
\hline $\begin{array}{l}\text { Dermatological } \\
\text { problems }\end{array}$ & $\begin{array}{l}\text { Congenital puffiness of hands and feet, increased melanocytic nevi, increased risk of keloid formation, premature } \\
\text { fine wrinkling of facial skin }\end{array}$ \\
\hline Neoplasm & $\begin{array}{l}\text { Colon cancer, gonadoblastoma, dysgerminoma, risk of endometrial carcinoma in patients with a history of } \\
\text { unopposed estrogen treatment }\end{array}$ \\
\hline
\end{tabular}

\section{TABLE 3: Clinical features of Turner's syndrome}

GERD: gastroesophageal reflux disease; IBD: inflammatory bowel disease

Of the clinical features associated with Turner's syndrome, our patient had short stature, a webbed neck, hypothyroidism, strabismus, a high arch palate, and excessive melanocytic nevi. After a diagnosis of Turner's syndrome is made, screening for other conditions associated with Turner's syndrome is necessary when clinically indicated.

\section{Conclusions}

Primary amenorrhea can result from various causes, and through broad vision, and proper and thorough clinical assessment, clinicians can timely diagnose and treat the cause of this condition. The reason for the delayed diagnosis in our case was most likely the low IQ of our patient and possibly socioeconomic issues. The learnings from this case report are as follows: primarily, in countries where healthcare-related awareness is limited and health resources are scarce, patients may present with one of the manifestations of Turner's syndrome. Clinicians from all specialties should be mindful of the characteristic clinical features of this uncommon entity and should do their best to make the best use of incidental clinical findings. Secondly, clinicians should employ extreme vigilance and thoroughness in their clinical assessment of patients with learning difficulties so that a clinical diagnosis of primary amenorrhea is not missed.

\section{Additional Information}

\section{Disclosures}

Human subjects: Consent was obtained or waived by all participants in this study. Shaukat Khanum Hospital Trust IRB issued approval EX-20-09-21-01. This study has been approved by the Shaukat Khanum Hospital Trust IRB. Conflicts of interest: In compliance with the ICMJE uniform disclosure form, all authors declare the following: Payment/services info: All authors have declared that no financial support was received from any organization for the submitted work. Financial relationships: All authors have declared that they have no financial relationships at present or within the previous three years with any organizations that might have an interest in the submitted work. Other relationships: All authors have declared that there are no other relationships or activities that could appear to have influenced the submitted work. 


\section{Cureus}

\section{References}

1. Kriplani A, Goyal M, Kachhawa G, Mahey R, Kulshrestha V: Etiology and management of primary amenorrhoea: a study of 102 cases at tertiary centre. Taiwan J Obstet Gynecol. 2017, 56:761-4

10.1016/j.tjog.2017.10.010

2. Seppä S, Kuiri-Hänninen T, Holopainen E, Voutilainen R: Management of endocrine disease: diagnosis and management of primary amenorrhea and female delayed puberty. Eur J Endocrinol. 2021, 184:R225-42. 10.1530/EJE-20-1487

3. Klein DA, Poth MA: Amenorrhea: an approach to diagnosis and management. Am Fam Physician. 2013, 87:781-8.

4. Kalaivani V, Gopalan U: Imperforate hymen: a case report. Int J Reprod Contracept Obstet Gynecol. 2021, 10:1172-4. 10.18203/2320-1770.ijrcog20210755

5. Kebaili S, Chaabane K, Mnif MF, et al.: Gonadal dysgenesis and the Mayer-Rokitansky-Kuster-Hauser Syndrome in a girl with a 46, XX karyotype: a case report and review of literature. Indian J Endocrinol Metab. 2013, 17:505-8. 10.4103/2230-8210.111663

6. Busey BR, Caro RJ, Nguyen DR: Primary amenorrhea: a Müllerian agenesis case report . Glob J Med Clin Case Rep. 2015, 2:30. 10.17352/2455-5282.000010

7. Sybert VP, McCauley E: Turner's syndrome. N Engl J Med. 2004, 351:1227-38. 10.1056/NEJMra030360 